\title{
Proteomics, toxicity and antivenom neutralization of Sri Lankan and Indian Russell's viper (Daboia russelii) venoms
}

\author{
Tasnim Faisal ${ }^{1}$, Kae Yi Tan² ${ }^{D}$, Nget Hong Tan², Si Mui Sim, Christeine Ariaranee Gnanathasan ${ }^{3}$, Choo Hock Tan ${ }^{1 *}$ (D) \\ ${ }^{1}$ Department of Pharmacology, Faculty of Medicine, University of Malaya, Kuala Lumpur, Malaysia. \\ ${ }^{2}$ Department of Molecular Medicine, Faculty of Medicine, University of Malaya, Kuala Lumpur, Malaysia. \\ ${ }^{3}$ Department of Clinical Medicine, Faculty of Medicine, University of Colombo, Colombo, Sri Lanka.
}

\section{Keywords:}

Geographical variation

Venomics

Antivenomics

Antivenom potency
* Correspondence: tanch@um.edu.my https://doi.org/10.1590/1678-9199-JVATITD-2020-0177 Received: 01 December 2020; Accepted: 17 February 2021; Published online: 30 April 2021

\begin{abstract}
Background: The western Russell's viper (Daboia russelii) is widely distributed in South Asia, and geographical venom variation is anticipated among distant populations. Antivenoms used for Russell's viper envenomation are, however, raised typically against snakes from Southern India. The present study investigated and compared the venom proteomes of $D$. russelii from Sri Lanka (DrSL) and India (DrI), the immunorecognition of Indian VINS Polyvalent Antivenom (VPAV) and its efficacy in neutralizing the venom toxicity.
\end{abstract}

Methods: The venoms of DrSL and DrI were decomplexed with $\mathrm{C}_{18}$ high-performance liquid chromatography and SDS-polyacrylamide gel electrophoresis under reducing conditions. The proteins fractionated were identified through nano-ESI-liquid chromatography-tandem mass spectrometry (LCMS/MS). The immunological studies were conducted with enzyme-linked immunosorbent assay. The neutralization of the venom procoagulant effect was evaluated in citrated human plasma. The neutralization of the venom lethality was assessed in vivo in mice adopting the WHO protocol.

Results: DrSL and DrI venom proteomes showed comparable major protein families, with phospholipases $\mathrm{A}_{2}$ (PLA ${ }_{2}$ ) being the most abundant ( $>60 \%$ of total venom proteins) and diverse (six protein forms identified). Both venoms were highly procoagulant and lethal (intravenous median lethal dose in mice, $\mathrm{LD}_{50}=0.24$ and $0.32 \mu \mathrm{g} / \mathrm{g}$, for DrSL and DrI, respectively), while lacking hemorrhagic and anticoagulant activities. VPAV was immunoreactive toward DrSL and DrI venoms, indicating conserved protein antigenicity in the venoms. The high molecular weight venom proteins were, however, more effectively immunorecognized than small ones. VPAV was able to neutralize the coagulopathic and lethal effects of the venoms moderately.

Conclusion: Considering that a large amount of venom can be injected by Russell's viper during envenomation, the potency of antivenom can be further improved for optimal neutralization and effective treatment. Region-specific venoms and key toxins may be incorporated into the immunization procedure during antivenom production. 


\section{Background}

Snakebite envenomation is an important public health threat that has been instated as a neglected tropical disease in 2017 by the World Health Organization (WHO) [1]. The disease burden of snakebite envenomation, however, continues to affect millions of impoverished populations to a great extent. The victims are typically people whose livelihoods are dependent on agriculture activities and have poor access to appropriate medical care for snakebite [2,3]. Indeed, snakebite envenomation has been aptly called the disease of poverty [4,5], although the epidemiology of snakebite remains lacking in many parts of the world. Global estimates indicated that there are 4.5-5.4 million people bitten by snakes a year, and that 1.8-2.7 millions of them develop clinical toxicity (snakebite envenomation) with a death toll that ranges from 81,000 to $138,000[3,6]$. Based on more recent communitybased studies [7-10], there is clear evidence that South Asia is one of the most heavily affected regions. In India alone, there were 2.8 million reported cases of snakebite annually with 46,900 deaths [7]. The neighboring country of Sri Lanka also shares a similar burden of snake envenomation, with approximately 80,000 snakebite cases reported and 400 deaths annually [8].

In Sri Lanka and India, the "Big Four" (Russell's viper, spectacled cobra, common Indian krait and saw-scaled viper) represent the four most common and medically important venomous snake species that cause snakebite envenomation $[2,3]$. However, widely distributed venomous species such as Russell's viper, are known to exhibit geographical variations in its venom composition [11-15]. Indeed, the composition of snake venom is influenced by various ecological factors; thus, it can vary significantly across the geographical distribution of the species as the snakes adapt to distinct habitats. The geographical variation of Russell's viper venom has been attributed as the cause of differences in the clinical features of envenomation reported in various regions [16].

Daboia russelii or the western Russell's viper is widespread throughout South Asia, including Pakistan, India, Bangladesh, Nepal, Sri Lanka, Bhutan [17], Jammu and Kashmir [18]. The snake is aggressive, ready to strike when provoked, and able to deliver a large amount of lethal venom with each bite. In view of its wide distribution and the high fatality of envenomation, D. russelii is considered as one of the deadliest snakes in South Asia [19,20]. The major manifestation of Russell's viper envenomation is hemostatic derangement that results in coagulopathy, internal hemorrhage, hypovolemic shock and major organ failure [21]. Besides causing hemotoxicity, Russell's viper envenoming in different geographical areas has also been reported to cause neurotoxicity [22], capillary leakage syndrome $[23,24]$, myotoxicity and acute kidney injury $[19,20,25,26]$ as well as pituitary infarction [16,27]. Apparently, the clinical manifestations of Russell's viper envenomation vary due to intra-species geographical variation in the venom composition. The geographical variation of venom also affects the efficacy of envenomation treatment, since the venom immunogen used in antivenom production was sourced from limited populations of Russell's viper in Southern India.

Hence, a comprehensive study of the geographical variation of snake venom is crucial. The advent of proteomics in recent years has greatly advanced the composition study of snake venom from diverse species $[28,29]$. A number of studies have reported the venom proteomes of $D$. russelii from various locales including Sri Lanka [13,30], Pakistan [11-13], Bangladesh [13] and the western (Haffkine Institute, Mumbai) [15], eastern (Burdwan and Nadia) [14] and southern (Irula Snake Catchers Society, ISCC) $[13,31]$ regions of India, using different proteomic platforms and quantitation approaches. These studies, collectively, demonstrated geographical variation in the venoms of Russell's viper from different locales. However, it is challenging to compare the proteomes, toxicity and neutralization of the venom samples from various locales when these studies adopted different experimental approaches. In some studies, data of protein subtypes/proteoforms and relative abundances were incomplete or unavailable. A good phylovenomic model was recently reported for the Russell's vipers from India, Sri Lanka, Pakistan and Bangladesh by Pla et al. [13], demonstrating that a standardized analytical approach is useful when investigating the venom variation. Following the proteomic study, it is also important to examine the neutralization activity of antivenom against all venom samples, so that the suitability of an antivenom for use in a particular region can be ascertained.

Although venom-induced toxicity can be circumvented by supportive treatment, antivenom remains the only definitive and effective treatment for snakebite envenomation [32]. In India, the antivenom products are usually formulated as polyvalent antivenoms against the "Big Four" species (Daboia russelii, Naja naja, Bungarus caeruleus, and Echis carinatus), produced by a few manufacturers. Of these, the Indian VINS polyvalent antivenom (VPAV) is one of the most commonly sourced products, which is also exported to neighboring countries such as Sri Lanka and Pakistan to meet the high local need for antivenom [33,34]. The Indian antivenom is raised against the "Big Four" of Indian origin, typically sourced from the Irula district of Tamil Nadu in South India. Thus, it is necessary to rigorously examine how effective the Indian antivenom is in neutralizing the toxic effects of the Sri Lankan D. russelii venom, besides comparing the venom compositions and immunological profiles between the two geographically separated populations of $D$. russelii. In this study, we characterized the venom proteome of Russell's viper originated from the northern, western and south-western regions of Sri Lanka. These were snakes implicated in real snakebite envenomation, brought to the hospital and authenticated by the herpetologist at the Snake Venom Research Laboratory \& Herpetarium (SVRL\&H), Faculty of Medicine, University of Colombo, Sri Lanka. The proteomic study was followed by an investigation of the immunoreactivity and neutralization 
capacity of VPAV, a widely used Indian antivenom product in the country. For comparison, the experiments were conducted in parallel with the Russell's viper venom of South Indian origin, which is used in the production of the Indian antivenom.

\section{Materials and methods}

\section{Materials}

Ammonium bicarbonate, iodoacetamide and dithiothreitol (DTT) were purchased from Sigma-Aldrich (USA). HPLC grade solvents, mass-spectrometry grade trypsin protease and Spectra $^{\text {mi }}$ Multicolor Broad Range Protein Ladder (10-260 kDa) were purchased from Thermo Scientific ${ }^{\mathrm{mt}}$ (USA). ExcelBand ${ }^{\mathrm{mw}}$ 3 color High Range Protein Marker (10-245 kDa) was purchased from SMOBIO (Taiwan). Millipore ZipTip ${ }^{\circ}$ C18 Pipette Tips were obtained from Merck (USA). Activated partial prothrombin time (APTT) and prothrombin time (PT) reagents were purchased from $\mathrm{R}^{2}$ Diagnostics (Swansea, UK). Other chemicals and reagents of analytical grade were purchased from Sigma-Aldrich (USA).

\section{Venoms and antivenom}

Daboia russelii venom of Sri Lanka was milked from multiple specimens originated from Anuradhapura (Northern region), Colombo (Western region), Ratnapura and Galle (Southwestern region) of the island country. The Indian sample of D. russelii venom was from Tamil Nadu region (South India) for comparative study. The lyophilized venom samples were stored at $-20^{\circ} \mathrm{C}$ until use. Indian VINS Polyvalent Antivenom (VPAV, Batch no:01AS12041) is the antivenom used in the current study. The antivenom was produced from the antisera of horses hyperimmunized against the venom of Indian "Big Four", i.e., D. russelii, N. naja, B. caeruleus and E. carinatus. The antivenom was reconstituted in $10 \mathrm{~mL}$ ultrapure water as per the manufacturer's instruction prior to use.

\section{Animal supply}

Albino mice of ICR strain (20-25 g) were supplied by the Animal Experimental Unit, Faculty of Medicine, University of Malaya. The protocol was approved by the Institutional Animal Care and Use Committee of the Faculty of Medicine, University of Malaya (Reference number: 20140911/PHAR/R/TCH) and carried out based on the Council for International Organizations of Medical Sciences (CIOMS) guidelines on animal experimentation [35].

\section{Determination of antivenom protein concentration}

Antivenom protein concentration (VPAV) was determined using bicinchoninic acid (BCA) protein assay kit (Thermo Scientific ${ }^{\text {mit }}$, USA), with bovine serum albumin (BSA) used as the protein standard calibrator. The antivenom concentration was expressed as mean \pm S.E.M. of triplicates.

\section{$C_{18}$ reverse-phase HPLC of the Sri Lankan and Indian $D$. russelii venom}

Three milligrams of lyophilized venoms were reconstituted in $0.1 \%$ TFA and fractionated by LiChrospher ${ }^{\circ} \mathrm{WP} 300 \mathrm{C}_{18}$ column (100 Å, $250 \mathrm{~mm} \times 4.6 \mathrm{~mm}$ ) using a Shimadzu LC-20AD HPLC system (Shimadzu, Co., Ltd. Japan). The proteins were eluted at a flow rate of $1 \mathrm{~mL} / \mathrm{min}$ [36] by Solvent B ( $0.1 \%$ TFA in $100 \%$ acetonitrile) with a linear gradient of $0-5 \%$ (10 $\mathrm{min})$, followed by $5-30 \%$ (20 $\mathrm{min}$ ), 30-55\% (120 min) and 50-70\% (20 min). Protein elution was monitored at $215 \mathrm{~nm}$, manually collected, pooled and subjected to SDS-PAGE and in-solution tryptic digestion. The digested peptides were then individually analyzed by shotgun proteomic analysis.

\section{SDS-PAGE of venom and eluted HPLC fractions}

Whole venoms $(50 \mu \mathrm{g})$ and HPLC-eluted venom fractions were electrophoresed with 15\% SDS-PAGE gel under reducing conditions at $90 \mathrm{~V}$ for $2 \mathrm{~h}$, according to Laemmli [37]. Proteins in the gel were stained using Coomassie Brilliant Blue R-250. The relative intensity of protein gel bands were determined using myImage Analysis software (Thermo Scientific ${ }^{\mathrm{Tm}}$, USA).

\section{Nano-electrospray-ionization-liquid chromatography tandem mass spectrometry (nano- ESI-LCMS/MS)}

The protein fractions obtained from RP-HPLC were reduced by DTT, alkylated by iodoacetamide, and digested by trypsin as previously described [38]. The trypsin-digested peptides were then desalted and extracted with Millipore Zip Tip and subjected to nano-ESI-LCMS/MS analysis, using an Agilent 1260 Infinity Nanoflow LC system (Agilent, USA) coupled to the AccurateMass Q-TOF 6550 series. The samples were reconstituted in 7 $\mu \mathrm{L}$ of $0.1 \%$ formic acid in water and loaded onto HPLC LargeCapacity Chip Column Zorbax 300-SB-C18 (160 nL enrichment column, $75 \mu \mathrm{m} \times 150 \mathrm{~mm}$ analytical column and $5 \mu \mathrm{m}$ particles) (Agilent, USA). One $\mu \mathrm{L}$ of the sample was injected and eluted at a flow rate of $0.4 \mu \mathrm{L} / \mathrm{min}$, with a linear gradient of $5-7 \%$ of solvent B (0.1\% formic acid in $100 \%$ acetonitrile). The drying gas flow used was $11 \mathrm{~L} / \mathrm{min}$ and the drying has temperature was $290^{\circ} \mathrm{C}$. Fragmentor voltage was set to $175 \mathrm{~V}$ and capillary voltage was set to 1800 V. Mass spectra were acquired using Mass Hunter acquisition software (Agilent, USA). Data with $\mathrm{MH}^{+}$mass range between 50 and $3000 \mathrm{Da}$ were collected and processed with Agilent Spectrum Mill MS Proteomics Workbench software package version B.04.00 against a merged database incorporating non-redundant NCBI database of Serpentes (taxid: 8570) and our in-house venom gland transcript database as previously described 
$[39,40]$. Carbamidomethylation and oxidized methionine were specified as a fixed modification and a variable modification, respectively. For protein validation, the following filtering parameters were applied: protein score $>20$, peptides score $>10$ and scored peak intensity (SPI) $>70 \%$. Identified proteins were further filtered to achieve a false discovery rate (FDR) $<1 \%$, and only proteins with at least 2 "Distinct Peptides" matched were considered significant for identification.

Protein $\mathrm{X}$ abundance in Fraction $\mathrm{Y}=\frac{\text { Mean spectral intensity of protein } \mathrm{X} \text { in Fraction } \mathrm{Y}}{\text { Total mean spectral intensity of all proteins in Fraction } \mathrm{Y}} \times$ Area under the curve of Fraction $\mathrm{Y}(\%)$

The relative abundance of protein $(\mathrm{X})$ eluted in chromatographic fraction (Y) was estimated based on the following formula as previously reported [36]:

\section{Data availability}

The mass spectrometry data of proteomics were deposited to the ProteomeXchange Consortium (http://proteomecentral. proteomexchange.org/) via the iProX partner repository [41], with the dataset identifier PXD019981.

\section{Immunological binding assay of antivenom}

The immunological binding activities of antivenom and venom antigens were examined using indirect enzyme-linked immunosorbent assay (ELISA) [42]. In brief, the immunoplate wells were pre-coated with $10 \mathrm{ng}$ venoms from $D$. russelii (Sri Lankan and Indian samples) and C. rhodostoma (Malaysian origin, used as negative control) overnight at $4{ }^{\circ} \mathrm{C}$. The venoms were then discarded, the wells were flicked dried and washed four times with phosphate-buffered saline containing $0.5 \%$ Tween 20 (PBST). Antivenom (VPAV) with a stock protein concentration of $20 \mathrm{mg} / \mathrm{mL}$ was prepared and serially diluted (1:300 to $1: 24300)$ in PBST. The antivenom preparations (100 $\mu \mathrm{L}$ ) were added into the venom-coated wells and incubated for $1 \mathrm{~h}$ at room temperature. The wells were washed four times with PBST, and horseradish peroxidase-conjugated anti-horse-IgG (Jackson ImmunoResearch Inc, USA) (1:8000 dilution) were then added into the wells. The wells were incubated for $1 \mathrm{~h}$ and then washed again before adding $100 \mu \mathrm{L}$ substrate $(0.5 \mathrm{mg} / \mathrm{mL}$ o-phenylenediamine and $0.006 \%$ hydrogen peroxide in $0.1 \mathrm{M}$ citrate-phosphate buffer, $\mathrm{pH}$ 5.0). The plate was left at room temperature in the dark for $30 \mathrm{~min}$. The reaction was terminated by adding $50 \mu \mathrm{L}$ of $12 \%$ sulfuric acid and the absorbance was read at $495 \mathrm{~nm}$ using Tecan M1000Pro Multimode plate reader (TECAN, Switzerland). The activity of venom-antivenom immunological binding was measured in absorbance unit, expressed in mean \pm S.E.M. of triplicate experiments. The half maximal concentration $\left(\mathrm{EC}_{50}\right)$ for the antivenom binding activity was defined as the concentration of antivenom that corresponding to half of the maximal absorbance.

\section{ELISA immunoprofiling of $D$. russelii venoms}

The venom protein fractions eluted from reverse-phase HPLC were freeze-dried and subsequently reconstituted in ultrapure water. Ten ng of venom proteins from each eluted fraction were coated on the immunoplates, followed by overnight incubation at $4{ }^{\circ} \mathrm{C}$. Indirect ELISA was performed as outlined above with an optimized VPAV antivenom dilution of 1:2700.

\section{Determination of procoagulant activity and neutralization by antivenom}

The procoagulant activity of venom was determined using human citrated plasma as substrate [12]. Fresh blood was collected into sodium citrate tubes and centrifuged at $1500 \mathrm{rpm}$ for $12 \mathrm{~min}$. Plasma was then aliquoted for assay use. Venom samples $(100 \mu \mathrm{L}$, diluted in phosphate buffer saline to various concentrations) were added into 96-microplate wells. Following this, the citrated human plasma $(100 \mu \mathrm{L})$ containing $40 \mu \mathrm{L} 0.4$ $\mathrm{M}$ calcium chloride $\left(\mathrm{CaCl}_{2}\right) / \mathrm{mL}$ was added simultaneously to the wells that contained venom samples. Coagulation activity was measured using the turbidimetric method as previously described [43], where the formulation of clots was real-time monitored at $405 \mathrm{~nm}$ absorbance at $37{ }^{\circ} \mathrm{C}$ for 15 minutes, using the Tecan M1000Pro Multimode plate reader (TECAN, Switzerland). The time for plasma clotting was taken as the time when the absorbance reading was $0.02 \mathrm{U}$ greater than the mean of the first two absorbance measurement. The minimum coagulation dose (MCD) is defined as the venom concentration that induces substrate coagulation in $3 \mathrm{~min}$.

In neutralization assay, the venom samples at a dose of $2 \mathrm{MCD}$ each were pre-incubated with various dilutions of VPAV at 37 ${ }^{\circ} \mathrm{C}$ for $30 \mathrm{~min}$. The total volume of venom-antivenom mixture was standardized at $50 \mu \mathrm{L}$. A hundred microliters of citrated human plasma (premixed with $40 \mu \mathrm{L} 0.4 \mathrm{M} \mathrm{CaCl}_{2} / \mathrm{mL}$ ) was then added simultaneously into the wells that contained the venomantivenom mixtures. The clotting time was then determined as described above. The effective dose (ED) of antivenom was defined as the dose of antivenom in volume $(\mu \mathrm{L})$ that prolonged the clotting time of the citrated human plasma to three times that of the control (2 MCD of venom, without antivenom). The efficacy was also expressed as an effective ratio in terms of venom amount $(\mu \mathrm{g})$ neutralized per microliter of antivenom $(\mu \mathrm{L})$ at the point corresponding to ED, using the following formula: 


\section{Determination of venom anticoagulant activity}

Fresh blood was collected into sodium citrate tubes and centrifuged at $1500 \mathrm{rpm}$ for $12 \mathrm{~min}$. Various dilutions of venoms were prepared in a final volume $15 \mathrm{uL}$ and loaded into 96-microplate well plate. One hundred fifty uL of pre-warmed plasma at $37^{\circ} \mathrm{C}$ was added into each well and incubated at $37^{\circ} \mathrm{C}$ for $2 \mathrm{~min}$. Twenty $\mathrm{uL}$ of $0.25 \mathrm{M} \mathrm{CaCl}_{2}$ was added to each well to induce clotting. Clotting time was recorded (milliseconds/ seconds). For negative control, plasma $(150 \mu \mathrm{L})$ was incubated with PBS $(15 \mathrm{uL})$. An extrinsic and intrinsic assay using APTT, and PT reagents were carried out with a modified method [44]. Anticoagulant activity of venom was determined based on its prolongation of negative control clotting time by $1 \mathrm{~s}$.

\section{Determination of venom lethality and neutralization by antivenom}

A hundred microliters of venom prepared at varying concentrations was injected intravenously (via the caudal vein) into mice, as previously described [12]. The mice were allowed access to food and water ad libitum. The survival ratio of the mice was recorded after $24 \mathrm{~h}$ and the $\mathrm{LD}_{50}$ was calculated using the Probit analysis method [45].

The potency of antivenom in neutralizing the lethality of venom was determined using an immunocomplexation method as described previously [42]. A challenge dose of the venom $\left(5 \mathrm{LD}_{50}\right)$ was preincubated with various dilutions of VPAV at $37{ }^{\circ} \mathrm{C}$ for $30 \mathrm{~min}$. The incubation mixture was then injected intravenously into the mice and the survival ratio of the mice

(A) DrSL

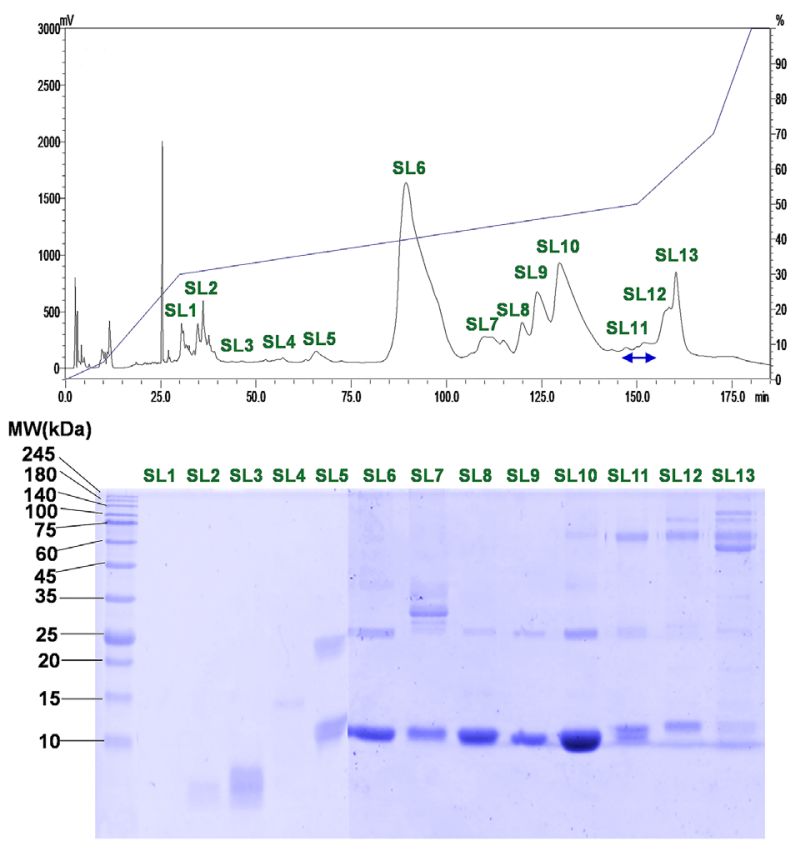

was recorded after $24 \mathrm{~h}$. The median effective dose $\left(\mathrm{ED}_{50}\right)$ of antivenom was expressed as the volume of antivenom in $\mu \mathrm{L}$ at which $50 \%$ of the challenged animals survived. Effective ratio $\left(\mathrm{ER}_{50}\right)$ was derived from $\mathrm{ED}_{50}$ and expressed as the ratio of venom to antivenom $(\mathrm{mg} / \mathrm{mL})$ at which $50 \%$ of the challenged animals survived. The neutralization potency $(\mathrm{P})$ of antivenom is defined as the amount of venom completely neutralized per unit volume of antivenom $(\mathrm{mg} / \mathrm{mL})$ was calculated accordingly [46]. The $\mathrm{P}$ (potency) value was then divided by the protein concentration of antivenom to obtain the "normalized potency" (n-P), defined as the amount of venom in mg completely neutralized per unit mass of antivenom proteins in gram [47].

\section{Statistical analysis}

Statistical significance of bioassay was analyzed with student t-test. In in vivo studies, the $\mathrm{LD}_{50}$ of the venom and $\mathrm{ED}_{50}$ of antivenom were expressed as means with $95 \%$ confidence interval (CI). The values were calculated using the Probit analysis method of Finney [45] with BioStat 2009 analysis software (AnalystSoft Inc., Canada).

\section{Results}

\section{Protein decomplexation and identification of $D$. russelii venoms}

Reverse-phase HPLC of Sri Lankan and South Indian D. russelii venoms yielded comparable chromatogram profiles, with 13 and 12 fractions eluted, respectively (Figure 1A, upper panel).

(B) $\mathrm{Drl}$

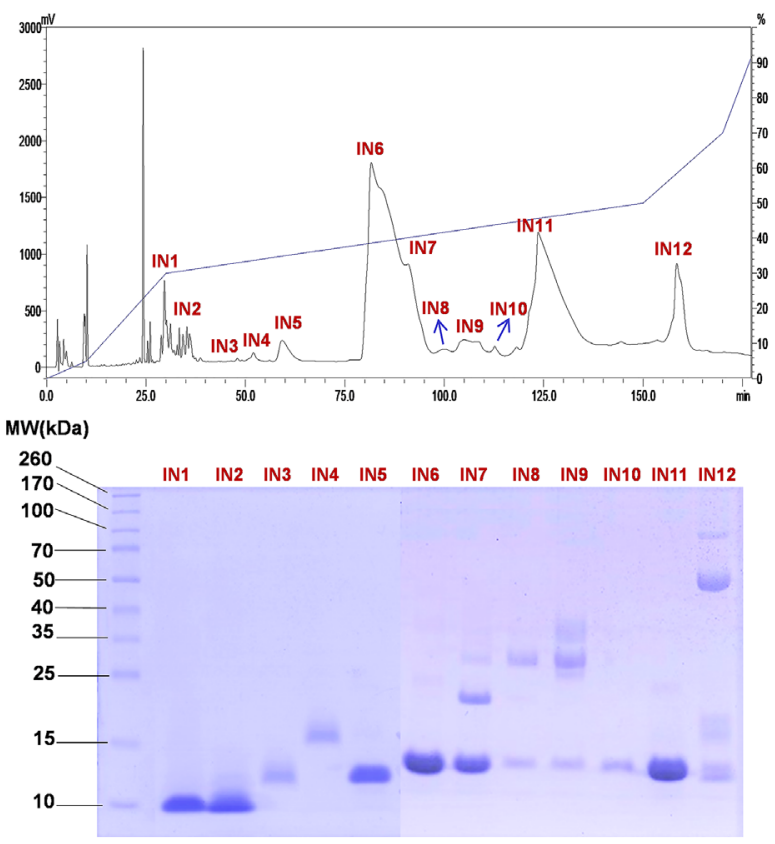

Figure 1. Protein decomplexation of snake venom: (A) DrSL, Sri Lankan Daboia russelii; (B) Drl, South Indian Daboia russelii. Upper panel: $C_{18}$ reverse-phase high-performance liquid chromatography (RP-HPLC) of Daboia russelii venoms (3 mg). Lower panel: 15\% SDS-PAGE of the venom fractions under reducing conditions. 
SDS-PAGE of the fractions under reducing conditions showed that the venoms were composed of proteins of diverse molecular masses ranging from less than $10 \mathrm{kDa}$ to $140 \mathrm{kDa}$ (Figure $1 \mathrm{~B}$, lower panel). Proteins identified within the respective fractions by nano-ESI-LCMS/MS were shown in Additional file 1 (Sri Lankan D. russelii, DrSL) and Additional file 2 (Indian D. russelii, DrI). The mass spectrometry data for each protein fraction analyzed were provided in Additional file 3.

The venom proteins detected, and their relative abundances were shown and compared between DrSL and DrI in Table 1. LCMS/MS analysis of the digested peptides and data mining categorized the venom proteins into 13 (DrSL) and 9 (DrI) protein families. Based on the HPLC chromatograms and SDS-PAGE, a distinct major protein band of approximately $13 \mathrm{kDa}$ was found in the HPLC fractions SL6 to SL10 (DrSL) and fractions IN6, IN7 and IN11 (DrI), as shown in Figure 1. These proteins corresponded to phospholipases $\mathrm{A}_{2}\left(\mathrm{PLA}_{2}\right)$ which accounted for $>60 \%$ of the total venom proteins, estimated based on the chromatographic peak area of the venoms (Figure 1) and the densitometry of venom SDS-PAGE (Figure $2 \mathrm{~A}$ ). Indeed, quantitation by mass spectrometry analysis showed that the $\mathrm{PLA}_{2}$ dominated both venom proteomes with a relative abundance of $63.92 \%$ (DrSL) and $67.5 \%$ (DrI) (Figure 2B), supporting that this enzymatic toxin family constituted the main bulk of proteins in both of the Russell's viper venoms. Other major protein components included snake venom metalloproteinase (SVMP) at 7.34\% for DrSL, and snake venom serine protease (SVSP) at $11.86 \%$ for DrI (Figure 2B). In comparison, DrI had a much higher abundance of SVSP (11.86\%) than DrSL (5.48\%), while the SVMP detected in DrI venom was much lower compared with DrSL. The smaller

Table 1. Overview of major protein families of Daboia russelii venoms from Sri Lanka, India and Pakistan examined under the same experimental conditions.

\begin{tabular}{|c|c|c|c|}
\hline \multirow[b]{2}{*}{ Protein family/major protein subfamilies* } & \multicolumn{3}{|c|}{ Relative abundance (\%) } \\
\hline & $\begin{array}{c}\text { Sri Lanka } \\
\text { (multiple locales) }\end{array}$ & $\begin{array}{c}\text { India } \\
\text { (South) }\end{array}$ & $\begin{array}{c}\text { Pakistan } \\
\text { (Sindh Delta)** }\end{array}$ \\
\hline Phospholipase $A_{2}\left(P L A_{2}\right)$ & $63.92 \%$ & $67.50 \%$ & $63.76 \%$ \\
\hline Basic phospholipase $A_{2}$ & $63.92 \%$ & $64.36 \%$ & $41.85 \%$ \\
\hline Acidic phospholipase $A_{2}$ & - & $3.14 \%$ & $21.92 \%$ \\
\hline Neutral Phospholipase $A_{2}$ & - & - & - \\
\hline Snake venom metalloproteinase (SVMP) & $7.34 \%$ & $0.19 \%$ & $2.52 \%$ \\
\hline Class PII & $0.19 \%$ & - & - \\
\hline P-lla sub-subfamily & $0.05 \%$ & - & - \\
\hline P-llb sub-subfamily & $0.14 \%$ & - & - \\
\hline Class PIII & $7.15 \%$ & $0.19 \%$ & $2.52 \%$ \\
\hline P-Illa sub-subfamily & $3.74 \%$ & - & - \\
\hline P-Illc sub-subfamily & $0.82 \%$ & - & - \\
\hline P-Illd sub-subfamily & $2.59 \%$ & $0.19 \%$ & $2.52 \%$ \\
\hline Snake venom serine protease (SVSP) & $5.48 \%$ & $11.86 \%$ & $5.5 \%$ \\
\hline Kunitz-type serine protease inhibitor (KSPI) & $3.03 \%$ & $5.41 \%$ & $16.0 \%$ \\
\hline Snaclec, C-type lectin \& C-type lectin-like protein (CTL) & $5.23 \%$ & - & $1.3 \%$ \\
\hline Cystein-rich secretory protein (CRiSP) & $\mathbf{5 . 9 7 \%}$ & $4.98 \%$ & $1.3 \%$ \\
\hline L-amino acid oxidase (LAAO) & $2.84 \%$ & $0.04 \%$ & $0.8 \%$ \\
\hline Snake venom metalloproteinase inhibitor (SMI) & $2.35 \%$ & - & - \\
\hline Venom endothelial growth factor (vEGF) & $2.16 \%$ & $1.55 \%$ & $4.3 \%$ \\
\hline Venom nerve growth factor (vNGF) & $0.97 \%$ & $1.68 \%$ & $1.1 \%$ \\
\hline Nucleotidase (5' NUC) & $0.45 \%$ & - & $0.1 \%$ \\
\hline Phosphodiesterase (PDE) & $0.21 \%$ & - & $2.5 \%$ \\
\hline Disintegrin (DIS) & - & $0.32 \%$ & - \\
\hline Moderate to high molecular weight proteins (MHp) & - & $6.47 \%$ & - \\
\hline Uncharacterized protein (UP) & - & - & $0.7 \%$ \\
\hline Aminopeptidase (AP) & $0.05 \%$ & - & - \\
\hline
\end{tabular}

*Protein names based on sequence similarity in UniProt database through BLAST search.

**The values were according to Faisalet al. [12] reported by the same laboratory. 
A)
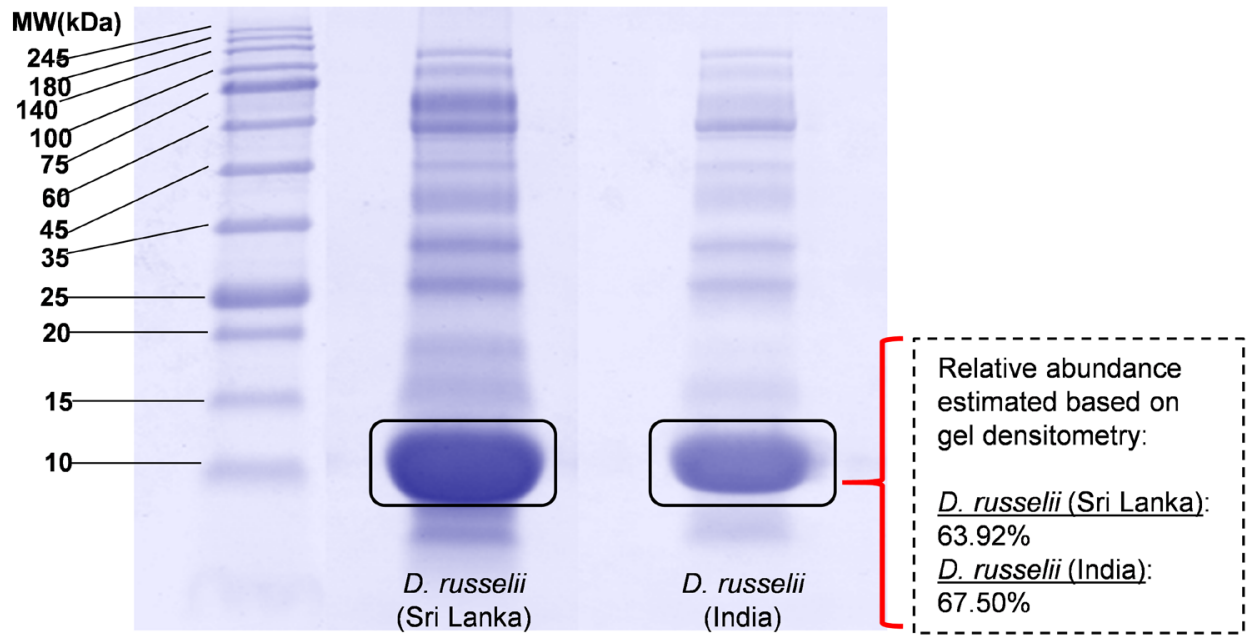

B)

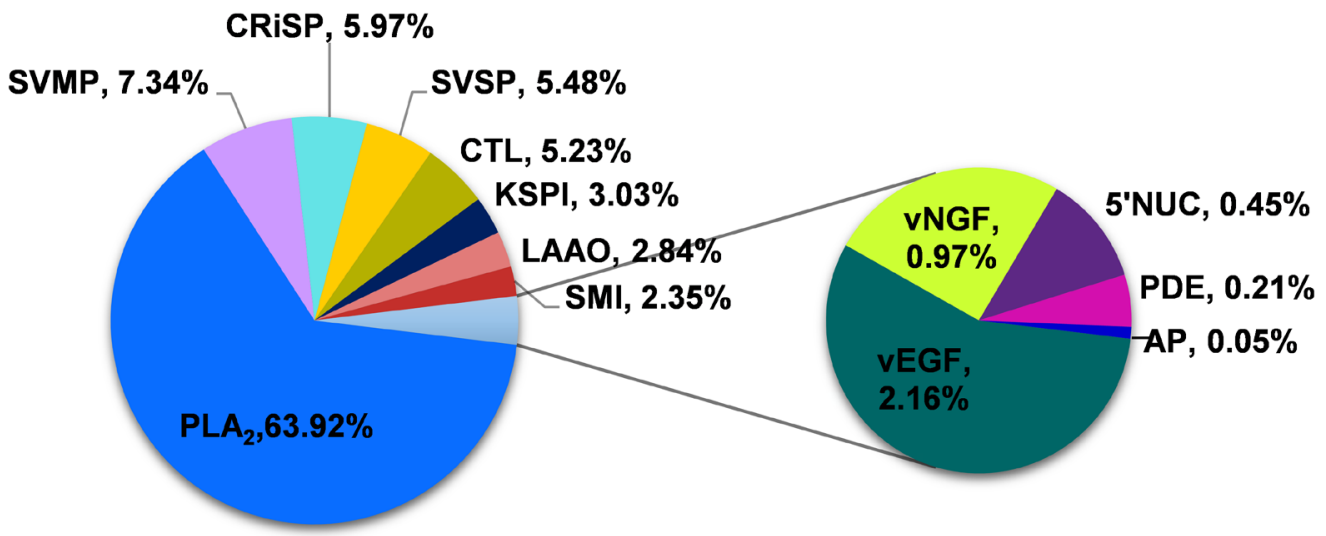

C)

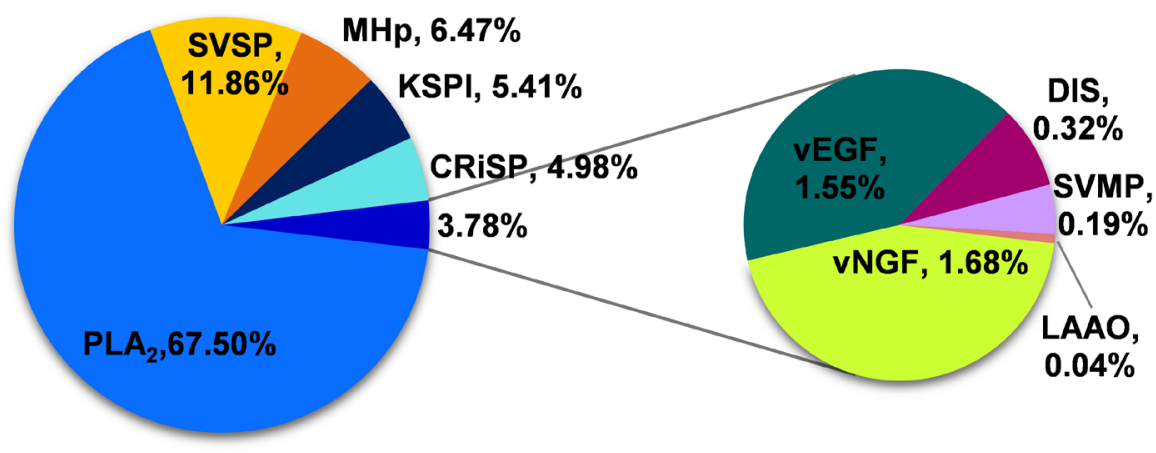

Figure 2. (A) Sodium dodecyl sulfate-polyacrylamide gel of Sri Lankan (left) and South Indian (right) D. russelii whole venoms, under reducing conditions. Gel intensity was measured by densitometry with the aid of mylmageAnalysis software. (B) Venom proteome with relative protein abundance of Sri Lankan Daboia russelii venom. (C) Venom proteome with relative protein abundance of South Indian Daboia russelii venoms. PLA : phospholipase $A_{2}$; SVMP: snake venom metalloproteinase; SVSP: snake venom serine protease; KSPI: Kunitz-type serine protease inhibitor; CRiSP: cysteine-rich secretory protein, SMI: snake venom metalloproteinase inhibitor; vNGF: nerve growth factor; vEGF: venom endothelial growth factor; Snaclec: snake venom C-type lectin/lectin-like proteins; PDE: phosphodiesterase; LAAO: L-amino acid oxidase; 5'-NUC: 5'-nucleotidase; MHp: moderate to high molecular weight proteins.

proteins of snake venom metalloproteinase inhibitor (SMI) and snaclec/C-type lectin/lectin-like proteins (CTL) were present in DrSL venom at $2.35 \%$ and $5.23 \%$ abundances, respectively, but undetected in DrI venom proteome. Both venoms contained similar abundances of cysteine-rich secretory protein (CRiSP, 5-6\%), venom nerve growth factor (vNGF, 1-2\%) and venom endothelial growth factor (vEGF, 1-2\%). DrSL venom contained high molecular weight proteins such as L-amino acid oxidase (LAAO) at $2.84 \%$ abundance, whereas 5 'nucleotidase (5'NUC) and phosphodiesterase (PDE) were found at trace amounts $(<$ $0.5 \%)$. On the other hand, the LAAO content in DrI venom was much lower $(<0.1 \%)$, while 5'NUC and PDE were undetected. A trace amount of aminopeptidase $(0.05 \%, \mathrm{AP})$ too was detected in DrSL venom. A small content of $\mathrm{PLA}_{2}(\sim 3 \%)$ was also eluted 
in DrI HPLC fraction 12 (IN12). In addition, SDS-PAGE of the fraction revealed 3 gel bands with low intensity (approximately $6 \%$ of protein abundance), ranging from moderate to high molecular weights. These proteins (labeled MHp) were not identifiable with repeated analysis of tandem mass spectrometry. Comparison with venom fraction SL13 of DrSL (also eluted at $150 \mathrm{~min}$, Figure 1A) suggested that the MHp proteins in IN12 fraction were likely isoforms of SVMP, 5-NUC', PDE and/or LAAO (Additional file 2).

A

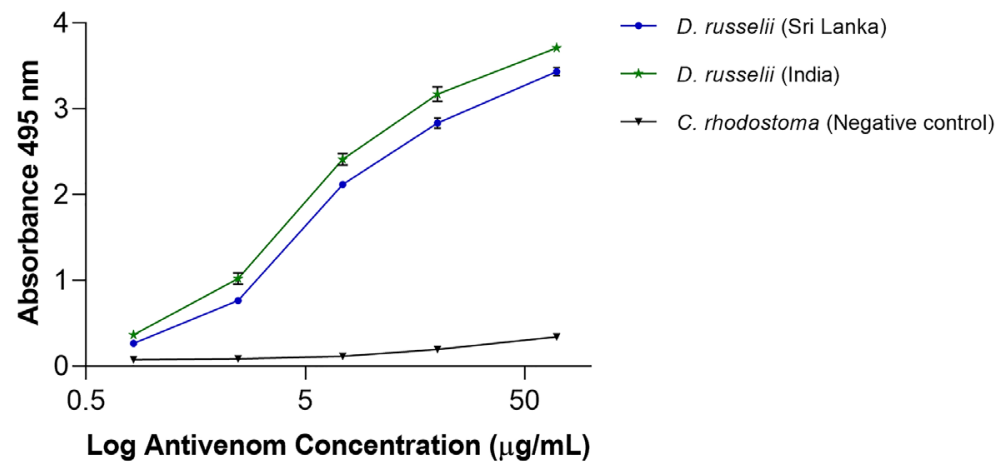

B
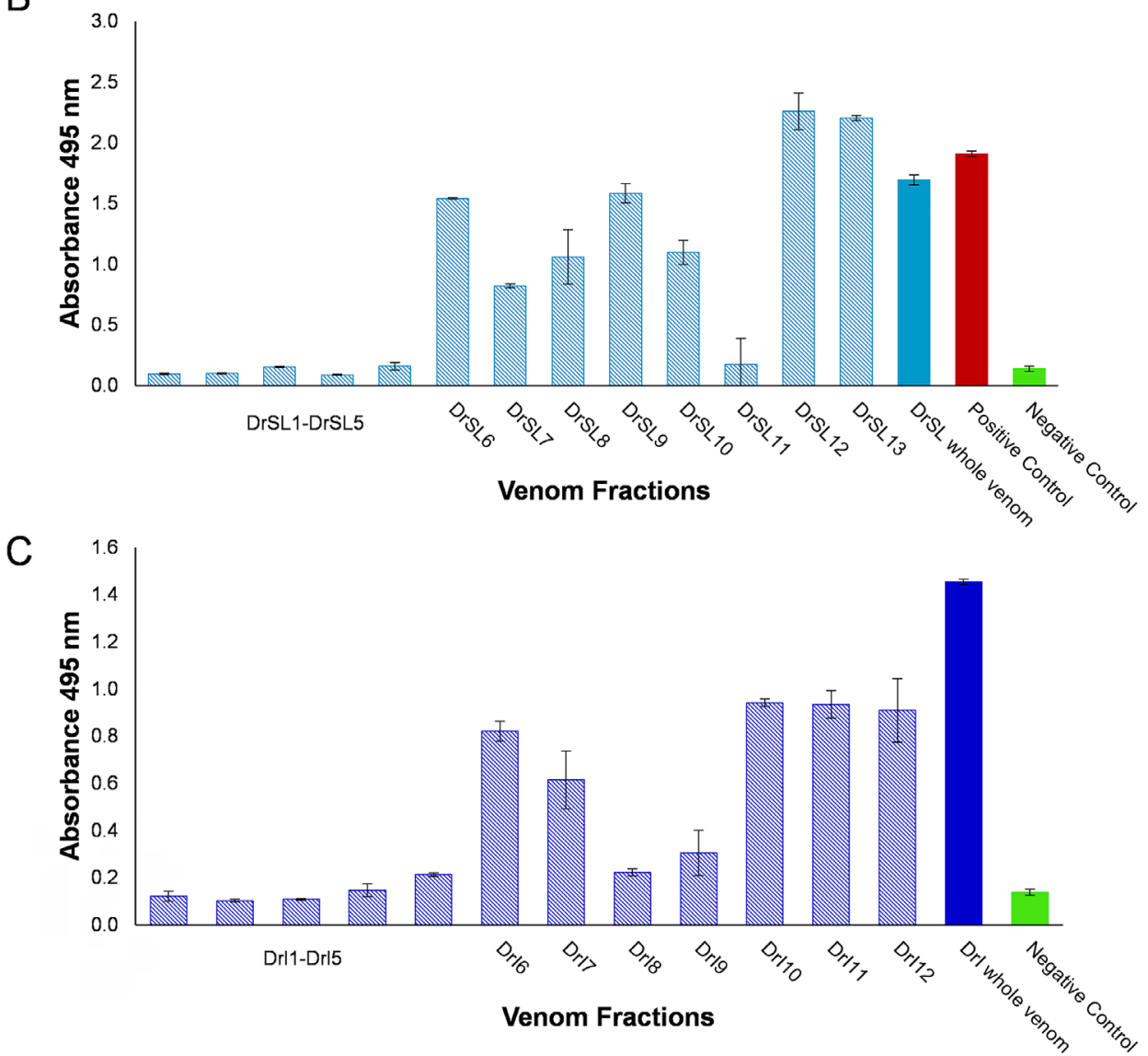

Figure 3. Immunological binding activity of the VPAV with (A) whole venoms of the Sri Lankan and South Indian Daboia russelii; (B) protein fractions of the venom eluted by reverse-phase HPLC (DrSL); (C) protein fractions of the venom eluted by reverse-phase HPLC (Drl). Indian D. russelii venom was used as positive control and Calloselasma rhodostoma venom as negative control. Absorbance values were obtained by indirect ELISA and expressed as mean \pm S.D. from three experiments.

\section{Antivenom protein concentration}

The protein concentration of reconstituted VINS Polyvalent Antivenom (VPAV) was determined to be $84.93 \pm 4.3 \mathrm{mg} / \mathrm{mL}$.

\section{Immunoreactivity of antivenom toward D. russelii venoms}

The immunological binding activity of VINS Polyvalent Antivenom (VPAV) increased dose-dependently toward both DrSL and DrI venoms (Figure 3A). Between the two venoms 
tested, the antivenom immunoreactivity binding activity was markedly higher toward DrI sample, as shown by a significantly lower half maximal effective concentration $\left(\mathrm{EC}_{50}\right)$ and a higher maximal absorbance $\left(\mathrm{E}_{\max }\right)$ (Table 2$)$.

\section{ELISA-based immuno-profiling of $D$. russelii venom protein fractions}

Figure $3 \mathrm{~B}$ and Figure $3 \mathrm{C}$ show the immunorecognition profile of VPAV toward the different HPLC fractions of DrSL and DrI venom proteins. All fractions were tested at a standard amount of $10 \mathrm{ng}$ proteins. The immunoreactivity of VPAV was consistently low (Abs < 0.3) toward the early eluted fractions (Fractions 1-5) while increasing toward the subsequent fractions of DrSL6-10 and DrI6-7. The highest immunoreactivity was shown in fractions DrSL12-13, and DrI10-12, which were HPLC fractions that contained larger proteins with moderate to high molecular weights (Figure 1).

\section{Procoagulant activities of $D$. russelii venoms and neutralization by antivenom}

The DrSL and DrI venoms both showed a dose-dependent procoagulant activity on human citrated plasma. The minimum coagulation doses (MCD) of the venoms were comparable at approximately $0.01 \mu \mathrm{g} / \mathrm{mL}$, and the procoagulant effects were effectively neutralized by VPAV (Table 3). The MCD and ED values were not significantly different between the two venoms $(p>0.05)$.

\section{Anticoagulant effect of $D$. russelii venoms}

When assayed with APTT and PT reagents, the D. russelii venoms did not exhibit anticoagulant activity. The venoms did not prolong or increase the clotting time of the D. russelii venoms at serial concentrations when compared with the negative control (plasma with APTT/PT reagent).

\section{Lethality and neutralization of $D$. russelii venoms}

The intravenous median lethal doses $\left(\mathrm{LD}_{50}\right)$ of DrSL and DrI venoms were 0.24 and $0.32 \mu \mathrm{g} / \mathrm{g}$, respectively. VPAV was effective in neutralizing the venom lethality of DrSL and DrI to comparable degrees, with potency values of $3.69 \mathrm{mg} / \mathrm{mL}$ and $3.76 \mathrm{mg} / \mathrm{mL}$ (amount of venom completely neutralized per milliliter of antivenom), respectively. The in vivo neutralization parameters tested were shown in Table 4.

Table 2. Immunological binding activities for Daboia russelii snake venoms against Indian VINS Polyvalent Antivenom (VPAV).

\begin{tabular}{lcc}
\hline Venom origin & $\mathbf{E C}_{\mathbf{5 0}}(\boldsymbol{\mu g} / \mathbf{m L})$ & $\mathbf{E}_{\max }$ (Absorbance) \\
\hline Daboia russelii (Sri Lanka) & $5.895 \pm 0.043 * 515 \pm 0.011 *$ \\
Daboia russelii (India) & $5.218 \pm 0.063 *$ & $3.797 \pm 0.044 *$ \\
\hline
\end{tabular}

Values were expressed as mean \pm S.E.M. from triplicate experiments. *Significant difference between venoms $(\mathrm{p}<0.05)$. EC : $_{50}$ concentration of antivenom at half value of absorbance max. $\mathrm{E}_{\max }$ : maximum absorbance at the highest antivenom concentration.

Table 3. Procoagulant and neutralization activity of Daboia russelii venoms with VPAV.

\begin{tabular}{|c|c|c|c|}
\hline Venom origin & $\begin{array}{l}\text { Minimum coagulation dose } \\
(M C D)(\mu g / m L)\end{array}$ & $\begin{array}{l}\text { Challenge dose } \\
(2 \mathrm{MCD})(\mu \mathrm{g} / \mathrm{mL})\end{array}$ & $\begin{array}{c}\text { Effective dose, } \\
\text { ED }(\mu g / \mu L)\end{array}$ \\
\hline Daboia russelii (Sri Lanka) & $0.0115 \pm 0.001$ & 0.023 & $\begin{array}{c}0.94 \\
(0.87-1.03)\end{array}$ \\
\hline Daboia russelii (India) & $0.0132 \pm 0.001$ & 0.026 & $\begin{array}{c}1.1 \\
(0.97-1.26)\end{array}$ \\
\hline
\end{tabular}

MCD was defined as the amount of venom that caused clotting in $1 \mathrm{~mL}$ of citrated human plasma in 3 min. Effective dose (ED): the venom amount ( $\mu$ g) neutralized per $(\mu \mathrm{L})$ of antivenom when the plasma coagulation time at 2 MCD was prolonged three times that of control (without antivenom). Results are presented as mean of triplicate \pm S.E.M.

Table 4. Lethality of Daboia russelii venoms (Sri Lanka and Southern India) and neutralization by VPAV (Indian Polyvalent Antivenom of VINS product).

\begin{tabular}{|c|c|c|c|c|c|}
\hline Venom & i.v. LD $_{50}(\mu \mathrm{g} / \mathrm{g})$ & $E D_{50}(\mu L$ of antivenom) & $E R_{50}(\mathrm{mg} / \mathrm{mL})$ & $P(\mathbf{m g} / \mathrm{mL})$ & $\mathrm{n}-\mathrm{P}$ (mg/g) \\
\hline Daboia russelii (Sri Lanka) & $\begin{array}{c}0.24 \\
(0.22-0.39)\end{array}$ & $\begin{array}{c}6.25 \\
(5.04-7.75)\end{array}$ & $\begin{array}{c}4.61 \\
(3.65-11.9)\end{array}$ & 3.69 & 43.4 \\
\hline Daboia russelii (India) & $\begin{array}{c}0.32 \\
(0.27-0.46)\end{array}$ & $\begin{array}{c}7.83 \\
(6.40-9.58)\end{array}$ & $\begin{array}{c}4.70 \\
(3.97-6.76)\end{array}$ & 3.76 & 44.3 \\
\hline
\end{tabular}

Intravenous median lethal dose (i.v. $\left.\mathrm{LD}_{50}\right)$ : Venom dose in $\mu \mathrm{g} / \mathrm{g}$ at which $50 \%$ of mice were dead. Median effective dose $\left(\mathrm{ED}_{50}\right)$ : Antivenom dose in $\mu \mathrm{L}$ at which $50 \%$ of mice survived the challenge dose of $5 \times L_{50}$. Median effective ratio $\left(E R_{50}\right)$ : Ratio of the amount of venom $(\mathrm{mg})$ to the volume dose of antivenom $(\mathrm{mL})$ at which $50 \%$ of mice survived. Potency $(\mathrm{P})$ : Amount of venom $(\mathrm{mg})$ that is completely neutralized by a unit volume $(\mathrm{mL})$ of antivenom. Normalized potency $(\mathrm{n}-\mathrm{P})$ : the amount of venom $(\mathrm{mg})$ that is completely neutralized per unit gram of antivenom protein.

Note: values in brackets are $95 \%$ confidence interval $(\mathrm{Cl})$ of $\mathrm{LD}_{50}, \mathrm{ED}_{50}$ and $\mathrm{ER}_{50}$ 


\section{Discussion}

The present proteomic study revealed that the venoms of $D$. russelii from Sri Lanka (DrSL) and Southern India (DrI) shared similar major protein families notwithstanding variations in their subtypes and relative abundances. The venom proteomes of DrSL and DrI consistently showed the dominance of phospholipase $\mathrm{A}_{2}\left(\mathrm{PLA}_{2}\right)$ at a strikingly high abundance of approximately $65 \%$ of total venom proteins. The PLA 2 abundance in Russell's viper venom has been a rather variable, disputable figure, ranging from as low as $\sim 22 \%$ to $70 \%$ of total venom proteins in various studies. The exceptionally high abundance of $\mathrm{PLA}_{2}(>60 \%)$, which also indicated its important role in envenomation, was first reported in the venom proteome of wild-caught Pakistani Russell's viper [12]. The high abundance observed is in contrast to the much lower values ( 20 to $30 \%$ ) reported previously for Russell's vipers from other sources, including Pakistan (captive specimens in Kentucky Reptile Zoo, USA, 32.8\%) [11], Mumbai (Western India, 32.5\%) [15], Burdwan (Eastern India, 22.2\%) and Nadia (Eastern India, 21.5\%) [14], which were also investigated with chromatographic approaches. Our findings of the exceptionally high PLA $\mathrm{A}_{2}$ abundances (current work and in Faisal et al. [12]) were, nonetheless, verified based on both chromatography (area under the curve) and gel densitometry, and were in agreement with the recent findings reported by Pla et al. [13] on specimens sourced from South India (70.6\%) and Sri Lanka (60.1\%). Together, the findings validated the abundance of $\mathrm{PLA}_{2}$ in western Russell's viper venom from the two locales. The remarkable variations noted in the captive Pakistani Russell's viper [11] and specimens from Western [15] and Eastern India [14] suggested possible evolutionary adaptation of the species to different ecological niches. A much lower "abundance" of PLA (23.8\%) was reported in another proteomic study on a South Indian Russell's viper venom sample [31], while it should be noted that the figure was non-quantitative (whereby the number of $\mathrm{PLA}_{2}$ was divided by the total number of all proteins detected), instead of relative abundance expressed in percentage of total protein weight. Meanwhile, the PLA 2 abundance reported earlier in a Sri Lankan specimen was approximately $35 \%$ based on a semi-quantitative method of 1D SDS-PAGE [30]. The method is probably less accurate for quantification purpose compared to the sequential use of HPLC and tandem mass spectrometry applied in most snake venomic studies $[48,49]$.

The dominance of $\mathrm{PLA}_{2}$ in the venom implies that the proteins play a significant pathophysiological role in Russell's viper envenomation. Snake venom PLA $_{2}$ can cause various complications resulted from its coagulopathic, plateletaggregation inhibitory, cytotoxic, myotoxic, neurotoxic, pro-inflammatory and hypotensive effects [50-53]. Further examination revealed that the PLA mainly consisted of basic PLA 2 subtypes (DrSL: $\sim 64 \%$; DrI: $\sim 68 \%$ ), with only a minute amount of acidic PLA in DrI $(\sim 3 \%)$ while undetected in DrSL. The basic PLA ${ }_{2}$ subtype VRV-PL-VIIIa (UniProt: P59071) is the major PLA identified in both DrSL (33.44\%) and DrI (58.45\%) venoms. VRV-PL-VIIIa is a coagulotoxin that binds to the activated factor $\mathrm{Xa}$, preventing it from forming the prothrombinase complex which is crucial in hemostatic regulation $[54,55]$. Its catalytic action that releases arachidonic acid from membrane phospholipids also inhibits platelet aggregation, thus worsening bleeding diathesis in envenomed patients [56,57]. Besides, VRVPL-VIIIa exhibited pre-synaptic neurotoxicity but its potency was low [58]. The proteomic finding also revealed that the basic PLA $_{2}$ U1-viperitoxin-Drla or viperitoxin (UniProt: P86368), which is the primary neurotoxin implicated in Russell's Viper envenoming in Sri Lanka [59], is the second most abundant PLA subtype found in the DrSL venom, constituting $22.78 \%$ of the total venom proteins. This pre-synaptic neurotoxin, however, was present minimally in the DrI venom (3.93\%). In addition, a $\mathrm{PLA}_{2}$ isoform homologous to the neurotoxic basic PLA, DsM-S1 (UniProt: A8CG84) [60] was also present at a higher abundance in the DrSL venom compared to DrI venom. The higher overall abundance of neurotoxic $\mathrm{PLA}_{2}$ detected in the DrSL venom proteome corroborates pre-synaptic neurotoxicity which is more commonly reported in Sri Lankan Russell's viper envenomation $[19,20,30,61]$.

The SVSP family was found more abundantly in the DrSL venom proteome (approximately 2 -fold higher) than DrI venom. The SVSP abundance in DrI venom is, however, comparable with that reported in another South Indian specimen [13], whereas specimens from other Indian locales (eastern and western regions) showed a more variable content of SVSP ( $\sim \%$ to $\sim 14 \%$ of total venom proteins) $[14,15]$. On the other hand, the SVSP abundances in DrSL (current work) and the wild Pakistani Russell's viper venom [12] were more consistent ( $5.5 \%)$. The presence of diverse SVSPs including fibrinogenases and thrombin-like enzymes in DrSL and DrI venoms supports the potent procoagulant effect of the venoms, and correlates clinically with consumptive coagulopathy. Both alpha- and beta-fibrinogenases were identified in the venom proteomes; these are arginine esterases that cleave fibrinopeptides A or B from the $\alpha$ - and $\beta$-chains of fibrinogen to form friable microclots of fibrin. The continuous hydrolysis of fibrinogen results in hypofibrinogenemia, leading to consumptive coagulopathy and hypovolemic shock [62]. Another major SVSP detected was RVV-V gamma (UniProt: P18965), a factor V activator that selectively cleaves the $\mathrm{Arg}^{1549}$-Ser ${ }^{1546}$ linkage in the human factor $\mathrm{V}$ molecule [63]. Activation of factor $\mathrm{V}$ elicits rapid coagulation in vitro while in vivo it results in defibrinogenation and anticoagulation [64], contributing to consumptive coagulopathy in Russell's viper envenomation.

Snake venom metalloproteinases (SVMP) are usually abundantly expressed in Asian pit viper venoms, constituting more than $30 \%$ of the proteomes $[65,66]$. The DrSL and DrI venoms, on the contrary, displayed low abundances of SVMP in their proteomes with remarkable intraspecific variations. The SVMP abundance in the DrSL venom (7.34\%) was comparable to that reported previously for Sri Lankan specimens (4.80-6.90\%) $[13,30]$. Marked geographical variation in SVMP, however, was observed across the various Indian specimens. The South 
Indian specimens had little SVMP $(<4 \%$, current work and Pla et al.) [13], whereas specimens from Eastern and Western India showed exceptionally high SVMP abundances (17.71-24.80\%) $[14,15]$. Despite the variable protein abundance, the major SVMP reported in these Russell's viper venom proteomes consistently belonged to the SVMP PIII subclass. Of the PIII SVMP detected, Factor X activating enzyme (RVV-X) was the most wellcharacterized subtype for its hemotoxic role in Russell's viper envenomation [67]. The metalloproteinase proteolytically cleaves the target bond in the factor X molecule, while the light-chain snaclecs form a secondary binding site specific for interaction with the Gla domain of factor $\mathrm{X}$, thus activating factor $\mathrm{X}$ and initiating blood coagulation [68]. Along with the procoagulant SVSPs, the factor X activator contributes to the exacerbation of venom-induced consumptive coagulopathy. Although PIII SVMP are typically 'hemorrhagins' (that induce hemorrhage through degradation of vascular basement membrane and capillaries) $[69,70]$, no significant dermal hemorrhagic activity of the venom was noted in this study. The procoagulant nature of the major PIII SVMP (RVV-X) and its low abundance in the Russell's viper venom shed light on the lack of local hemorrhagic effect in mice as shown in this study and a previous report [71]. The finding is also consistent with clinical observations in which Russell's viper envenomation typically causes systemic hemorrhage rather than localized bleeding [19,20,72,73].

The abundances of KSPI were comparable between the Sri Lankan (3.03-5.35\%) and South Indian (2.40-5.41\%) specimens, but more variable in the specimens from Western and Eastern India (12.50-22.90\%), Pakistan (16.00-28.40\%) and Bangladesh (7.90\%). KSPIs were known to exhibit pro-inflammatory, serine protease-inhibiting and hemotoxic (potentially anticoagulant) properties [74-76]. Other venom proteins detected were generally less than $5 \%$ per protein family in the venoms, with abundances that were more variable across the different geographical specimens. These include CRiSP, CTL (snaclecs), vNGF, LAAO, vEGF, '5NUC, PDE, DIS and SMI, which may serve ancillary functions such as anti-platelet, cytotoxic and proinflammatory activities.

Preceding reports showed that D. russelii envenomation in Sri Lanka and South India caused capillary leakage syndrome (CLS), a pathological condition triggered by increased vascular permeability secondary to endothelial damage. This results in edema formation, hypoalbuminemia and intravascular shock $[19,77]$. It was proposed that CLS is caused by the formation of lysophosphatidic-inflammatory metabolites (PLA 2 activity), apoptosis (LAAO activity) and direct damage to the capillary basement membrane by SVMP [23], as well as the action of vEGF that increases vascular permeability $[78,79]$. The presence of vEGF in DrSL and DrI in the present work, together with the copious $\mathrm{PLA}_{2}$ and other pro-inflammatory toxins, likely contribute to the distinct pathology of CLS reported in Russell's viper envenomation in Sri Lanka and South India.

The study also showed that DrSL and DrI venoms were highly potent in inducing plasma coagulation, consistent with the substantial amount of procoagulant SVSP and SVMP in the venom proteomes. The findings revealed that the procoagulant activity of $D$. russelii venoms is calcium-dependent, in line with the model proposed by Morita [68] which suggested that $\mathrm{Ca}^{2+}$ ions are needed to induce a conformational change in the gammacarboxyglutamate domain of Factor $\mathrm{X}$ for it to be recognized by the procoagulant toxin [67]. Interestingly, anticoagulant activity was not detected in the venoms of DrSL and DrI, consistent with the study reported by Prasad et al. [71] (Southern and Western Indian D. russelii specimens). Nevertheless, a PLA isoform isolated from $D$. russelii venom (Pakistani origin) had been shown to possess in vitro anticoagulant activity previously [80]. The absence of in vitro anticoagulant activity in the whole venom could be explained by the potent procoagulant activity of the venom overweighing the in vitro anticoagulant effect of the venom. Clinically, it is anticipated that Russell's viper envenomation leads to coagulopathic complication through multiple pathways including the consumption of various clotting factors by the potent procoagulant enzymes (hence, consumptive coagulopathy), and direct anticoagulant effect from anticoagulant toxins in the venom [81,82].

In mice, DrSL and DrI venoms both exhibited potent lethality (i.v. $\mathrm{LD}_{50}=\sim 0.2-0.3 \mu \mathrm{g} / \mathrm{g}$ ), similar to that observed in the specimens from Pakistan and Bangladesh $(\sim 0.19 \mu \mathrm{g} / \mathrm{g})[12,13]$. Clinically, Russell's viper envenomation in humans is extremely deadly with a fatality rate of $37.9 \%$, as reported earlier in central India [83]. Findings from the immunoreactivity study revealed conserved protein antigenicity in both DrSL and DrI venoms, supporting the effective binding of VPAV to the venom proteins. Further immunorecognition profiling inferred that VPAV was more immunoreactive toward HPLC fractions that contained abundant PLA 2 , SVSP and SVMP. These proteins were the major components detected in the proteomes, and the main culprit toxins implicated in the pathophysiology of Russell's viper envenomation $[11,12,14,15,31]$. Nevertheless, the antivenom exhibited low immunoreactivity toward early eluted fractions (Fractions 1-5) which were made up of, primarily, low molecular mass proteins. The observation is consistent with previous reports which suggested that small venom proteins are less antigenic, thus antivenom immunoreactivity is generally low toward toxins of low molecular mass $[12,66,84,85]$.

Essentially, an effective antivenom must be able to neutralize the major toxins present in the venom, so that the principal toxicity manifested in envenomation can be mitigated or reversed. In this regard, VPAV effectively inhibited the procoagulant activity of DrSL and DrI venoms, implying that the antivenom was able to neutralize the main procoagulant venom proteins such as SVMP (e.g. FXa/RVV-X activator heavy chain) [86], SVSP (e.g. RVV-V toxins) [87] and CTL (e.g. coagulation FXa light chain) [88]. The efficacy of VPAV was further evaluated in vivo with the WHO recommended 'gold standard' protocol of neutralization in mice [89]. In the present work, we found that the efficacy of VPAV in neutralizing the lethality of DrI and DrSL venoms is modest, consistent with that reported for specimens 
from Pakistan (unspecified locale) and Sri Lanka (unspecified locale) $[13,90,91])$. The in vivo neutralization of Indian Russell's viper venoms was, however, not reported previously and thus could not be compared with our current finding. These preclinical data thus far indicated that the Indian polyvalent antivenom could neutralize the lethality of Sri Lankan and Indian D. russelii venoms to different extents.

Taken together, the neutralization findings (from the present work and previous studies) indicate that protein epitopes were largely conserved in Russell's viper venoms sampled from various locales in South Asia. The neutralization potency of antivenom, however, may be optimized with region-specific venoms used as immunogens during antivenom production $[89,92]$. The approach of toxin-targeted antivenom production, where species-specific principal toxins are used as or added to the immunogen mixture, may also improve the specificity and potency of the antivenom. From the practical standpoint, assuming that an adult Indian Russell's viper injects $100 \mathrm{mg}$ venom per bite (author's experience in venom milking), the antivenom neutralization potency of approximately $3.6 \mathrm{mg} /$ $\mathrm{mL}$ (equivalent to $36 \mathrm{mg} / \mathrm{vial}$ ) indicates that at least 3 vials of antivenom will be needed in the initial dosing regimen. In practice, additional doses are typically required as the toxins are slowly absorbed into the systemic circulation from the bite site while the antivenom is simultaneously eliminated from the body. Clinically, the recommended therapeutic dose of VPAV for patients envenomed by Russell's viper in Sri Lanka is 10 vials of the antivenom given as an infusion in normal saline over one hour. If the coagulopathy persists (indicated by incoagulable blood on 20-minute whole blood clotting test, 20WBCT) after 6 hours, an additional 10 vials of antivenom will be administered. This underscores the need for antivenom with a higher potency to ensure that effective neutralization can be achieved with a lower dose of antivenom, which in turn will reduce the cost of treatment and the risk of hypersensitive reaction. Findings from antivenomics and toxin-fraction immunoreactivity studies should provide further insights into the improvement of antivenom production [48]. In this context, we propose that key toxins should be identified and derived from the respective geographical specimens to formulate a new immunogen recipe that can efficiently elicit neutralizing antibodies against the targeted toxins [93].

\section{Conclusion}

The venoms of D. russelii from Sri Lanka (DrSL) and South India (DrI) showed comparable proteomic profiles, with PLA 2 constituting the most abundant and diverse proteins. Intraspecific venom variation was minor and mainly involved proteins with ancillary functions. Both DrSL and DrI venoms were highly procoagulant and lethal, consistent with the pathophysiology of Russell's viper envenomation. The Indian antivenom, VPAV, showed comparable binding activity toward both venoms, and modestly neutralized the procoagulant as well as the lethal effects of the venoms. It is anticipated that improving the neutralization potency of the antivenom will lead to optimal dosing, thus reducing the cost of treatment and the risk of hypersensitive reaction. This may be achieved by selectively identifying and incorporating the principal toxins of venoms from various regions into the immunogen formulation, thus producing an antivenom with pan-regional, wider geographical utility.

\section{Acknowledgments}

The authors acknowledge VINS BioProducts Ltd, India, for the antivenom supply.

\section{Availability of data and materials}

Data generated and analyzed during this study were included in this published article.

\section{Funding}

The present study was supported by research grants BKS0032020 from the University of Malaya, and PV058-2018 from the UMSC CA.R.E Fund.

\section{Competing interests}

The authors declare that they have no competing interests.

\section{Authors' contributions}

CHT and NHT conceived the study and designed experiments. CHT, TKY, SSM and CAG participated in the study design and methodology. CHT, KYT, SSM and CAG provided resources. TF performed experiments and analysis of data. CHT, KYT and TF interpreted and curated the data. CHT and TF wrote the main article. All authors read, revised and approved the final manuscript.

\section{Ethics approval}

The present study was approved by the Institutional Animal Care and Use Committee of the Faculty of Medicine, University of Malaya (reference number: 20140911/PHAR/R/TCH) and carried out based on the Council for International Organizations of Medical Sciences (CIOMS) guidelines on animal experimentation.

\section{Consent for publication}

Not applicable.

\section{Supplementary material}

The following online material is available for this article:

Additional file 1. Protein assignment of Sri Lankan Daboia russelii (DrSL) venom by fractions of reversed-phase HPLC. Data were generated from ESI-LCMS/MC analysis of in-solution digested peptides. 
Additional file 2. Protein assignment of Indian Daboia russelii (DrI) venom by fractions of reversed-phase HPLC. Data were generated from ESI-LCMS/MC analysis of in-solution digested peptides.

Additional file 3. Mass spectrometry information of Sri Lankan and Indian Daboia russelii HPLC-eluted venom fractions from nano-ESI-LCMS/MS.

\section{References}

1. Chippaux JP. Snakebite envenomation turns again into a neglected tropical disease! J Venom Anim Toxins incl Trop Dis. 2017 Sep 28;23(1):38. http:// dx.doi.org/10.1186/s40409-017-0127-6.

2. Alirol E, Sharma SK, Bawaskar HS, Kuch U, Chappuis F. Snake bite in South Asia: a review. PLoS Negl Trop Dis. 2010 Jan;4(1):e603.

3. Gutiérrez JM, Calvete JJ, Habib AG, Harrison RA, Williams DJ, Warrell DA. Snakebite envenoming. Nat Rev Dis Primers. 2017 Sep 14;3:17063.

4. Gutiérrez JM, Theakston RDG, Warrell DA. Confronting the neglected problem of snake bite envenoming: the need for a global partnership. PLoS Med. 2006 Jun;3(6):e150.

5. Harrison RA, Hargreaves A, Wagstaff SC, Faragher B, Lalloo DG. Snake envenoming: a disease of poverty. PLoS Negl Trop Dis. 2009 Dec 22;3(12):e569.

6. Kasturiratne A, Wickremasinghe AR, de Silva N, Gunawardena NK, Pathmeswaran A, Premaratna R, et al. The global burden of snakebite: a literature analysis and modelling based on regional estimates of envenoming and deaths. PLoS Med. 2008 Nov 4;5(11):e218.

7. Mohapatra B, Warrell DA, Suraweera W, Bhatia P, Dhingra N, Jotkar RM, et al. Snakebite mortality in India: a nationally representative mortality survey. PLoS Negl Trop Dis. 2011 Apr 12;5(4):e1018.

8. Ediriweera DS, Kasturiratne A, Pathmeswaran A, Gunawardena NK, Wijayawickrama BA, Jayamanne SF, et al. Mapping the risk of snakebite in Sri Lanka - a national survey with geospatial analysis. PLoS Negl Trop Dis. 2016 Jul 8;10(7):e0004813.

9. Rahman R, Faiz MA, Selim S, Rahman B, Basher A, Jones A, et al. Annual incidence of snake bite in rural Bangladesh. PLoS Negl Trop Dis. 2010 Oct 26;4(10):e860.

10. Khan MS. The snakebite problem in Pakistan. Bull Chicago Herp Soc. 2014 Jan;49:165-7.

11. Mukherjee AK, Kalita B, Mackessy SP. A proteomic analysis of Pakistan Daboia russelii russelii venom and assessment of potency of Indian polyvalent and monovalent antivenom. J Proteomics. 2016 Jul 20;144:73-86.

12. Faisal T, Tan KY, Sim SM, Quraishi N, Tan NH, Tan CH. Proteomics, functional characterization and antivenom neutralization of the venom of Pakistani Russell's viper (Daboia russelii) from the wild. J Proteomics. 2018 Jul 15;183:1-13.

13. Pla D, Sanz L, Quesada-Bernat S, Villalta M, Baal J, Chowdhury MAW, et al. Phylovenomics of Daboia russelii across the Indian subcontinent. Bioactivities and comparative in vivo neutralization and in vitro thirdgeneration antivenomics of antivenoms against venoms from India, Bangladesh and Sri Lanka. J Proteomics. 2019 Sep;207:103443.

14. Kalita B, Patra A, Das A, Mukherjee AK. Proteomic analysis and immunoprofiling of eastern India Russell's Viper (Daboia russelii) venom: correlation between RVV composition and clinical manifestations post RV bite. J Proteome Res. 2018 Aug 3;17(8):2819-33.

15. Kalita B, Patra A, Mukherjee AK. Unraveling the proteome composition and immuno-profiling of Western India Russell's Viper venom for in-depth understanding of its pharmacological properties, clinical manifestations, and effective antivenom treatment. J Proteome Res. 2016 Feb 3;16(2):583-98.

16. Thorpe RS, Pook CE, Malhotra A. Phylogeography of the Russell's viper (Daboia russelii) complex in relation to variation in the colour pattern and symptoms of envenoming. Herpetol J. 2007 Oct;17(4):209-18.

17. Lenz N. Von Schmetterlingen und Donnerdrachen-Natur und Kultur in Bhutan. Karlsruher Naturhefte. 2012.
18. Goursi UH, Abir MK, Mehmood A. Occurrence of Russell's chain viper Daboia Russelii Russelii in Deva Vatala National Park, Azad Jammu and Kashmir. Int J Conserv Sci. 2017 Jan;8(2):281-8.

19. Warrell DA. Snake venoms in science and clinical medicine 1. Russell's viper: biology, venom and treatment of bites. Trans R Soc Trop Med Hyg. 1989 Nov-Dec;83(6):732-40.

20. Kularatne SAM. Epidemiology and clinical picture of the Russell's viper (Daboia russelii russelii) bite in Anuradhapura, Sri Lanka: a prospective study of 336 patients. Southeast Asian J Trop Med Public Health. 2003 Dec;34(4):855-62.

21. Waiddyanatha $S$, Silva A, Siribaddana S, Isbister GK. Long-term effects of snake envenoming. Toxins (Basel). 2019;11(4):193.

22. Warrell D. In Handbook of Clinical Toxicology of Animal Venoms and Poisons. Meier, J, White J, editor's. CRC Press, New York, USA. P. 433-92.1995.

23. Udayabhaskaran V, Thomas EA, Shaji B. Capillary leak syndrome following snakebite envenomation. Indian J Crit Care Med. 2017 Oct;21(10):698-702.

24. Kendre PP, Jose MP, Varghese AM, Menon JC, Joseph JK. Capillary leak syndrome in Daboia russelii bite-a complication associated with poor outcome. Trans R Soc Trop Med Hyg. 2018 Feb 1;112(2):88-93.

25. Ariaratnam CA, Sheriff MHR, Arambepola C, Theakston RDG, Warrell DA. Syndromic approach to treatment of snake bite in Sri Lanka based on results of a prospective national hospital-based survey of patients envenomed by identified snakes. Am J Trop Med Hyg. 2009 Oct;81(4):72531.

26. De Silva A, Ranasinghe L. Epidemiology of snake-bite in Sri Lanka: a review. Ceylon Med J. 1983 Sep;28(3):144-54.

27. Naik BN, Bhalla A, Sharma N, Mokta J, Singh S, Gupta P, et al. Pituitary dysfunction in survivors of Russell's viper snake bite envenomation: $A$ prospective study. Neurol India. 2018 Sep-Oct;66(5):1351-8.

28. Calvete JJ, Sanz L, Angulo Y, Lomonte B, Gutiérrez JM. Venoms, venomics, antivenomics. FEBS lett. 2009 Jun 5;583(11):1736-43.

29. Calvete JJ. Next-generation snake venomics: protein-locus resolution through venom proteome decomplexation. Expert Rev Proteomics. 2014 Jun;11(3):315-29.

30. Tan NH, Fung SY, Tan KY, Yap MKK, Gnanathasan CA, Tan CH. Functional venomics of the Sri Lankan Russell's viper (Daboia russelii) and its toxinological correlations. J Proteomics. 2015 Oct 14;128:403-23.

31. Sharma M, Das D, lyer JK, Kini RM, Doley R. Unveiling the complexities of Daboia russelii venom, a medically important snake of India, by tandem mass spectrometry. Toxicon. 2015 Dec 1;107(Pt B):266-81.

32. Chippaux J. Guidelines for the production, control and regulation of snake antivenom immunoglobulins. Biologie aujourd'hui. 2010;204(1):87-91.

33. Simpson ID, Norris RL. Snake antivenom product guidelines in India:"The devil is in the details". Wilderness Environ Med; 2007;18(3):163-8.

34. Whitaker $\mathrm{R}$, Whitaker $\mathrm{S}$. Venom, antivenom production and the medically important snakes of India. Curr Sci. 2012 Sep 25;103(6):635-43.

35. Howard-Jones N. CIOMS ethical code for animal experimentation. ICLAS bulletin. 1986.

36. Tan CH, Tan KY, Yap MKK, Tan NH. Venomics of Tropidolaemus wagleri, the sexually dimorphic temple pit viper: Unveiling a deeply conserved atypical toxin arsenal. Sci Rep. 2017;7:43237.

37. Laemmli UK. Cleavage of structural proteins during the assembly of the head of bacteriophage T4. Nature. 1970 Aug 15;227(5259):680-5.

38. Tan $\mathrm{CH}$, Wong KY, Tan KY, Tan NH. Venom proteome of the yellowlipped sea krait, Laticauda colubrina from Bali: Insights into subvenomic diversity, venom antigenicity and cross-neutralization by antivenom. J Proteomics. 2017 Aug 23;166:48-58.

39. Tan KY, Tan $\mathrm{CH}$, Chanhome L, Tan NH. Comparative venom gland transcriptomics of Naja kaouthia (monocled cobra) from Malaysia and Thailand: elucidating geographical venom variation and insights into sequence novelty. PeerJ. 2017 Apr 5;5:e3142.

40. Chong HP, Tan KY, Tan NH, Tan CH. Exploring the diversity and novelty of toxin genes in Naja sumatrana, the Equatorial spitting cobra from Malaysia through de novo venom-gland transcriptomics. Toxins (Basel). 2019 Feb 11;11(2):104. 
41. Ma J, Chen T, Wu S, Yang C, Bai M, Shu K, et al. iProX: an integrated proteome resource. Nucleic Acids Res. 2019 Jan 8;47(D1):D1211-7.

42. Tan CH, Tan NH, Tan KY, Kwong KO. Antivenom cross-neutralization of the venoms of Hydrophis schistosus and Hydrophis curtus, two common sea snakes in Malaysian waters. Toxins (Basel). 2015 Feb 16;7(2):572-81.

43. O'Leary MA, Isbister GK. A turbidimetric assay for the measurement of clotting times of procoagulant venoms in plasma. J Pharmacol Toxicol Methods. 2010 Jan-Feb;61(1):27-31.

44. Sharma M, lyer JK, Shih N, Majumder M, Mattaparthi VSK, Mukhopadhyay $R$, et al. Daboxin p, a major phospholipase $A 2$ enzyme from the indian Daboia russelii russelii venom targets factor $x$ and factor $x a$ for its anticoagulant activity. PloS One. 2016;11(4):e0153770.

45. Finney DJ, Tattersfield F. Probit analysis: Cambridge University Press; Cambridge; 1952.

46. Araujo H, Bourguignon S, Boller M, Dias A, Lucas E, Santos I, et al. Potency evaluation of antivenoms in Brazil: the national control laboratory experience between 2000 and 2006. Toxicon. 2008 Mar 15;51(4):502-14.

47. Tan CH, Tan KY. Functional application of snake venom proteomics in in vivo antivenom assessment. Functional Proteomics: Springer. p. 153-8. 2019.

48. Lomonte B, Calvete JJ. Strategies in 'snake venomics' aiming at an integrative view of compositional, functional, and immunological characteristics of venoms. J Venom Anim Toxins incl Trop Dis. 2017;23(1):26. doi: 10.1186/ s40409-017-0117-8.

49. Tan $\mathrm{CH}$, Tan $\mathrm{KY}$, Tan NH. A protein decomplexation strategy in snake venom proteomics. Methods Mol Biol. 2019;1871:83-92.

50. Kasturi S, Gowda TV. Purification and characterization of a major phospholipase A2 from Russell's viper (Vipera russelli) venom. Toxicon. 1989;27(2):229-37.

51. Gowda TV, Middlebrook JL. Effects of myonecrotic snake venom phospholipase A2 toxins on cultured muscle cells. Toxicon. 1993 Oct;31(10):1267-78.

52. Gutiérrez JM, Lomonte B. Phospholipases A2: Unveiling the secrets of a functionally versatile group of snake venom toxins. Toxicon. 2013 Feb;62:27-39.

53. Huang HC, Lee C. Isolation and pharmacological properties of phospholipases A2 from Vipera russelli (Russell's viper) snake venom. Toxicon. 1984;22(2):207-17.

54. Faure G, Gowda VT, Maroun RC. Characterization of a human coagulation factor Xa-binding site on Viperidae snake venom phospholipases A 2 by affinity binding studies and molecular bioinformatics. BMC Struct Biol. 2007 Dec 6;7(1):82.

55. Tsai IH, Lu PJ, Su JC. Two types of Russell's viper revealed by variation in phospholipases A2 from venom of the subspecies. Toxicon. 1996 Jan;34(1):99-109.

56. Rumbaut R, Thiagarajan P. Platelet recruitment and blood coagulation. Platelet-Vessel Wall Interactions in Hemostasis and Thrombosis. 2010.

57. Markland FS. Snake venoms and the hemostatic system. Toxicon. 1998 Dec;36(12):1749-800.

58. Gowda VT, Schmidt J, Middlebrook JL. Primary sequence determination of the most basic myonecrotic phospholipase A2 from the venom of Vipera russelli. Toxicon. 1994 Jun;32(6):665-73.

59. Silva A, Kuruppu S, Othman I, Goode RJ, Hodgson WC, Isbister GK. Neurotoxicity in Sri Lankan Russell's viper (Daboia russelii) envenoming is primarily due to U1-viperitoxin-Dr1a, a pre-synaptic neurotoxin. Neurotox Res. 2017 Jan;31(1):11-9.

60. Tsai IH, Tsai HY, Wang YM, Warrell DA. Venom phospholipases of Russell's vipers from Myanmar and eastern India-Cloning, characterization and phylogeographic analysis. Biochim Biophys Acta. 2007 Aug;1774(8):1020-8.

61. Silva A, Maduwage K, Sedgwick M, Pilapitiya S, Weerawansa P, Dahanayaka NJ, et al. Neurotoxicity in Russell's viper (Daboia russelii) envenoming in Sri Lanka: A clinical and neurophysiological study. Clin Toxicol. 2016 Jun;54(5):411-9.

62. Mackessy SP. Handbook of venoms and toxins of reptiles: CRC press; 2016.

63. Tokunaga F, Nagasawa K, Tamura S, Miyata T, Iwanaga S, Kisiel W. The factor $\mathrm{V}$-activating enzyme (RVV-V) from Russell's viper venom.
Identification of isoproteins RVV-V alpha,- $\mathrm{V}$ beta, and- $\mathrm{V}$ gamma and their complete amino acid sequences. J Biol Chem. 1988 Nov 25;263(33):1747181.

64. Mukherjee AK. The pro-coagulant fibrinogenolytic serine protease isoenzymes purified from Daboia russelii russelii venom coagulate the blood through Factor $\mathrm{V}$ activation: role of glycosylation on enzymatic activity. PloS One. 2014;9(2):e86823.

65. Tan CH, Tan KY, Ng TS, Quah ES, Ismail AK, Khomvilai S, et al. Venomics of Trimeresurus (Popeia) nebularis, the Cameron Highlands pit viper from Malaysia: Insights into venom proteome, toxicity and neutralization of antivenom. Toxins (Basel). 2019 Feb 6;11(2):95.

66. Liew JL, Tan NH, Tan $\mathrm{CH}$. Proteomics and preclinical antivenom neutralization of the mangrove pit viper (Trimeresurus purpureomaculatus, Malaysia) and white-lipped pit viper (Trimeresurus albolabris, Thailand) venoms. Acta Trop. 2020 Sep;209:105528.

67. Takeya H, Nishida S, Miyata T, Kawada S, Saisaka Y, Morita T, et al. Coagulation factor $X$ activating enzyme from Russell's viper venom (RVV-X). A novel metalloproteinase with disintegrin (platelet aggregation inhibitor)-like and C-type lectin-like domains. J Biol Chem. 1992 Jul 15;267(20):14109-17.

68. Morita T. Proteases which activate factor $X$. Enzymes from Snake Venoms Fort Collins: Alaken. 1998:179-209.

69. Markland FS, Swenson S. Snake venom metalloproteinases. Toxicon. 2013;62:3-18.

70. Escalante T, Rucavado A, Gutiérrez J. Snake venom metalloproteinases. Biological roles and participation in the pathophysiology of envenomation. Handbook of venoms and toxins of reptiles. p.115-38. 2009.

71. Prasad NB, Uma B, Bhatt SK, Gowda VT. Comparative characterisation of Russell's viper (Daboia/Vipera russelli) venoms from different regions of the Indian peninsula. Biochim Biophys Acta. 1999 Aug 5;1428(2-3):121-36.

72. Phillips RE, Theakston RDG, Warrell DA, Galigedara Y, Abeysekera D, Dissanayaka $P$, et al. Paralysis, rhabdomyolysis and haemolysis caused by bites of Russell's viper (Vipera russelli pulchella) in Sri Lanka: failure of Indian (Haffkine) antivenom. Q J Med. 1988 Sep;68(3-4):691-715.

73. Mahasandana S, Rungruxsirivorn Y, Chantarangkul V. Clinical manifestations of bleeding following Russell's viper and Green pit viper bites in adults. Southeast Asian J Trop Med Pub Health. 1980;11(2):285-93.

74. Guo CT, McClean S, Shaw C, Rao PF, Ye MY, Bjourson AJ. Trypsin and chymotrypsin inhibitor peptides from the venom of Chinese Daboia russellii siamensis. Toxicon. 2013 Mar 1;63:154-64.

75. Mashiko $\mathrm{H}$, Takahashi $\mathrm{H}$. Cysteine proteinase inhibitors in elapid and hydrophiid snake venoms. Toxicon. 2002;40(9):1275-81.

76. Mukherjee AK, Mackessy SP, Dutta S. Characterization of a Kunitz-type protease inhibitor peptide (Rusvikunin) purified from Daboia russelii russelii venom. Int J Biol Macromol. 2014 Jun;67:154-62.

77. Warrell DA. Snake bite. The Lancet. 2010;375(9708):77-88.

78. Sirois MG, Edelman E. VEGF effect on vascular permeability is mediated by synthesis of platelet-activating factor. Am J Physiol. 1997 Jun;272(6):H2746-H56.

79. Rucavado A, Escalante T, Camacho E, Gutiérrez JM, Fox JW. Systemic vascular leakage induced in mice by Russell's viper venom from Pakistan. Sci Rep. 2018;8(1):16088.

80. Mukherjee AK. A major phospholipase A2 from Daboia russelii russelii venom shows potent anticoagulant action via thrombin inhibition and binding with plasma phospholipids. Biochimie. 2014 Apr;99:153-61.

81. Mukherjee AK. Characterization of a novel pro-coagulant metalloprotease (RVBCMP) possessing a-fibrinogenase and tissue haemorrhagic activity from venom of Daboia russelli russelli (Russell's viper): Evidence of distinct coagulant and haemorrhagic sites in RVBCMP. Toxicon. 2008 Apr;51(5):923-33.

82. Thakur R, Chattopadhyay P, Ghosh SS, Mukherjee AK. Elucidation of procoagulant mechanism and pathophysiological significance of a new prothrombin activating metalloprotease purified from Daboia russelii russelii venom. Toxicon. 2015 Jun 15;100:1-12. 
83. Chaudhari TS, Patil TB, Paithankar MM, Gulhane RV, Patil MB. Predictors of mortality in patients of poisonous snake bite: experience from a tertiary care hospital in central India. Int J Crit Inj Sci. 2014 Apr;4(2):101-7.

84. Patra A, Kalita B, Chanda A, Mukherjee AK. Proteomics and antivenomics of Echis carinatus carinatus venom: Correlation with pharmacological properties and pathophysiology of envenomation. Sci Rep. 2017;7(1):1-17.

85. Lingam TMC, Tan KY, Tan $\mathrm{CH}$. Proteomics and antivenom immunoprofiling of Russell's viper (Daboia siamensis) venoms from Thailand and Indonesia.J Venom Anim Toxins incl Trop Dis. 2020;26. http://dx.doi.org/10.1590/16789199-jvatitd-2019-0048.

86. Kini R, Koh C. Metalloproteases affecting blood coagulation, fibrinolysis and platelet aggregation from snake venoms: Definition and nomenclature of interaction sites. Toxins (Basel). 2016 Sep 29;8(10):284.

87. Swenson S, Markland Jr FS. Russell's viper venom factor $\vee$ activator. Handbook of Proteolytic Enzymes: Elsevier. p. 3036-8. 2013.

88. Chen HS, Chen JM, Lin CW, Khoo KH, Tsai IH. New insights into the functions and $\mathrm{N}$-glycan structures of factor $\mathrm{X}$ activator from Russell's viper venom. FEBS J. 2008 Aug;275(15):3944-58.
89. World Health Organization. Guidelines for the production, control and regulation of snake antivenom immunoglobulins Replacement of Annex 2 of WHO Technical Report Series. N. 964. p. 197-388. 2017.

90. Maduwage K, Silva A, O'Leary MA, Hodgson WC, Isbister GK. Efficacy of Indian polyvalent snake antivenoms against Sri Lankan snake venoms: lethality studies or clinically focussed in vitro studies. Sci Rep. 2016;6:26778.

91. Villalta M, Sánchez A, Herrera M, Vargas M, Segura Á, Cerdas M, et al. Development of a new polyspecific antivenom for snakebite envenoming in Sri Lanka: Analysis of its preclinical efficacy as compared to a currently available antivenom. Toxicon. $2016 \mathrm{Nov} ; 122: 152-9$

92. Theakston RDG, Warrell D, Griffiths E. Report of a WHO workshop on the standardization and control of antivenoms. Toxicon. 2003 Apr;41(5):541-57.

93. Ratanabanangkoon K, Tan KY, Eursakun S, Tan $\mathrm{CH}$, Simsiriwong $\mathrm{P}$, Pamornsakda $\mathrm{T}$, et al. A simple and novel strategy for the production of a pan-specific antiserum against elapid snakes of Asia. PLoS Negl Trop Dis. 2016 Apr 8;10(4):e0004565. 